\title{
Window operation behaviour and indoor air quality during lockdown: A monitoring-based simulation-assisted study in London
}

Building Serv. Eng. Res. Technol. $1-17$

(C) The Author(s) 2021

(c) (i)

Article reuse guidelines: sagepub.com/journals-permissions DOI: 10.1 I77/014362442 II017786 journals.sagepub.com/home/bse

@SAGE

\section{Farhang Tahmasebi $\mathbb{D}$, Yan Wang, Elizabeth Cooper, Daniel Godoy Shimizu (D), Samuel Stamp and Dejan Mumovic}

\begin{abstract}
The Covid-19 outbreak has resulted in new patterns of home occupancy, the implications of which for indoor air quality (IAQ) and energy use are not well-known. In this context, the present study investigates 8 flats in London to uncover if during a lockdown, (a) IAQ in the monitored flats deteriorated, (b) the patterns of window operation by occupants changed, and (c) more effective ventilation patterns could enhance IAQ without significant increases in heating energy demand. To this end, one-year's worth of monitored data on indoor and outdoor environment along with occupant use of windows has been used to analyse the impact of lockdown on IAQ and infer probabilistic models of window operation behaviour. Moreover, using on-site $\mathrm{CO}_{2}$ data, monitored occupancy and operation of windows, the team has calibrated a thermal performance model of one of the flats to investigate the implications of alternative ventilation strategies. The results suggest that despite the extended occupancy during lockdown, occupants relied less on natural ventilation, which led to an increase of median $\mathrm{CO}_{2}$ concentration by up to 300 ppm. However, simple natural ventilation patterns or use of mechanical ventilation with heat recovery proves to be very effective to maintain acceptable IAQ.

Practical application: This study provides evidence on the deterioration of indoor air quality resulting from homeworking during imposed lockdowns. It also tests and recommends specific ventilation strategies to maintain acceptable indoor air quality at home despite the extended occupancy hours.
\end{abstract}

\section{Keywords}

Indoor air quality (iaq), occupant behaviour, window operation, building performance simulation, Covid 19 lockdown

Received 2I February 202I; Revised I4 April 202I; Accepted 27 April 202I

UCL Institute for Environmental Design and Engineering, University College London, London, UK
Corresponding author:

Farhang Tahmasebi, UCL Institute for Environmental Design and Engineering, University College London, UK.

Email: f.tahmasebi@ucl.ac.uk 


\section{Introduction}

The Covid-19 lockdowns across the globe mean that people spend much more time in their homes, where concentrations of several pollutants, including human associated particulate matter (PM), volatile organic compounds (VOCs), carbon monoxide (CO), and carbon dioxide $\left(\mathrm{CO}_{2}\right)$ can be several times higher than outdoor air, depending upon outdoor levels, building envelope air tightness and indoor sources, indicating a significant potential for detrimental health impacts. ${ }^{1-3}$

There are two factors that make $\mathrm{CO}_{2}$ concentrations relevant to ventilation and IAQ standards: their relation to indoor levels of bioeffluents and associated odours (an important factor in perceived air quality and occupant satisfaction), and their relation to ventilation rates per person. Specifically, concentrations of $\mathrm{CO}_{2}$ in occupied indoor spaces are often higher than concentrations found outdoors because people produce and exhale $\mathrm{CO}_{2}$. Declining air change rates per person increase the magnitude of this indoor-outdoor difference in $\mathrm{CO}_{2}$ concentration allowing for peak indoor $\mathrm{CO}_{2}$ concentrations above outdoor levels to be used as rough, albeit imperfect indicators for outdoorair ventilation rate per occupant. ${ }^{4}$

Direct health effects of $\mathrm{CO}_{2}$ on humans have been reported at concentrations much higher than those found in normal indoor settings. For example, Lipsett et al. ${ }^{5}$ suggest that $\mathrm{CO}_{2}$ concentrations higher than $20,000 \mathrm{ppm}$ cause changes in breathing. According to epidemiologic and intervention studies, higher levels of $\mathrm{CO}_{2}$ within the range found in normal indoor settings (i.e. up to $5000 \mathrm{ppm}$ ), are associated with perceptions of poor air quality, increased prevalence of acute health symptoms (e.g. headache, poorer work performance, and increased absenteeism (e.g.). ${ }^{6-8} \mathrm{It}$ is debated whether these associations exist because the higher indoor $\mathrm{CO}_{2}$ concentrations are correlated with higher levels of other indoor-generated pollutants which are the causative agents of the adverse effects. ${ }^{9,10}$ Yet, as suggested by Chatzidiakou et al., ${ }^{11}$ $\mathrm{CO}_{2}$ concentration can be used as a useful proxy for occupant-related contaminants.

Moreover, other studies have underlined the direct negative impacts of $\mathrm{CO}_{2}$ on occupants, in the range of concentrations typically found in buildings. For example, Kajtar et al. ${ }^{12}$ reported that controlled human exposures to $\mathrm{CO}_{2}$ between $2000 \mathrm{ppm}$ and $5000 \mathrm{ppm}$, with ventilation rates unchanged, were positively associated with perception of wellbeing and performance on some reading tasks. More recently, a study by Xu et al. ${ }^{13}$ found that sleep quality was negatively affected by increasing concentrations of $\mathrm{CO}_{2}$ up to $3000 \mathrm{ppm}$. Moreover, Mishra et al. ${ }^{14}$ showed that with lower $\mathrm{CO}_{2}$ levels, the number of awakenings throughout the night tended to decrease. Another study found that seven of nine aspects of work performance were significantly and negatively impacted by a $\mathrm{CO}_{2}$ level of $2500 \mathrm{ppm} .{ }^{15}$ It should be noted, however, that two small studies (one with 10 healthy collegeaged volunteers and another with 25 similarly aged participants) presented findings that did not demonstrate an increase in physical symptoms or in a decline in office related tasks from levels of $\mathrm{CO}_{2}$ (without bioeffluents) of up to 5000 ppm. ${ }^{16,17}$

In another strand of research, to address the challenges of modelling energy demand and IAQ with building performance simulation tools, understanding and modelling of occupants' operation of windows has gained momentum in the last two decades. ${ }^{14,18,19}$ Specifically, a number of studies have introduced probabilistic models of window operation, which could explain the occupants' interactions with windows based on statistically significant indoor and outdoor environmental parameters. ${ }^{20,21}$ 
Arguably, the above-mentioned studies have become especially relevant as the extraordinary circumstances associated with the Covid-19 outbreak has resulted in unprecedented patterns of household occupancy. If people continue to spend more time at home following the 2020 global pandemic, it will be more critical to ensure that IAQ in houses meets the recommended standards without excessive energy use. To this end, the present study benefits from one-year's worth of monitored data to reveal the impact of the lockdown on IAQ and patterns of opening and closing windows by occupants. Moreover, the study deploys calibrated building performance simulation to investigate the potential of different ventilation strategies. For the purpose of the present paper, the monitoring-based study explores the concentrations of $\mathrm{CO}_{2}, \mathrm{PM}_{10}$ and $\mathrm{PM}_{2.5}$ and the simulation-based tests focus on $\mathrm{CO}_{2}$ concentration as a proxy for IAQ.

\section{Method}

\section{Monitored data}

During the first enforced lockdown in London in spring 2020, the authors took advantage of remote access to a set of monitoring devices in eight occupied flats in East London, which were part of an investigation since before the outbreak (see Table 1). The flats were located within three buildings at two sites in a dense urban area near major, highly trafficked, roadways. Mean annual $\mathrm{PM}_{2.5}$ levels in these locations is greater than $20-22 \mu \mathrm{g} / \mathrm{m}^{3}$ and mean nitrogen dioxide levels can exceed $50 \mu \mathrm{g} / \mathrm{m}^{3}$ according to publicly available monitoring at the sites by Imperial College London. The study used a dataset collected from July 2019 to June 2020 including solar irradiance, wind speed and wind direction, indoor and outdoor air temperature, relative humidity, concentrations of

Table I. The monitoring equipment and specifications.

\begin{tabular}{|c|c|c|c|c|}
\hline Parameter & Sensor & Range & Resolution & Accuracy \\
\hline Temperature & Thermistor & $-30.0^{\circ} \mathrm{C}$ to $65.0^{\circ} \mathrm{C}$ & $0.1^{\circ} \mathrm{C}$ & $\begin{array}{l} \pm 0.2^{\circ} \mathrm{C} \text { at } 20^{\circ} \mathrm{C} \\
\pm 0.4^{\circ} \mathrm{C} \text { for }-5^{\circ} \mathrm{C} \text { to } \\
\quad 40^{\circ} \mathrm{C}\end{array}$ \\
\hline Relative humidity & Capacative & $0.0 \%-100.0 \%$ & $0.10 \%$ & $\begin{array}{l} \pm 2 \%(0 \% \text { to } 90 \% R H) \\
\pm 4 \%(0 \% \text { to } 100 \% R H)\end{array}$ \\
\hline $\mathrm{CO}_{2}$ & $\begin{array}{l}\text { Non-dispersive infra-red } \\
(E+E \text { Electronik) }\end{array}$ & 0-5000 ppm & Ippm & $< \pm 50 \mathrm{ppm},+3 \%$ \\
\hline $\begin{array}{l}\text { Particulate Matter } \\
\qquad \mathrm{PM}_{1}, \mathrm{PM}_{2.5}, \mathrm{PM}_{10}\end{array}$ & $\begin{array}{r}\text { Optical Particle Counter } \\
\text { (Alphasense OPC-N2) }\end{array}$ & $\begin{array}{l}0.35 \text { to } 40 \mu \mathrm{m} \\
0.00 \text { to } 500.00 \mu \mathrm{g} / \mathrm{m}^{3}\end{array}$ & $0.01 \mu g / \mathrm{m}^{3}$ & $\begin{array}{l}\text { Agreement with refer- } \\
\text { ence instruments: } \\
\text { RMSE } 2-6 \mu g / \mathrm{m}^{3} \\
\text { and } R^{2} \text { values of } \\
\text { between } 0.75-1.0 \text {. }\end{array}$ \\
\hline Occupancy & PIR (HOBO UX90) & $\begin{array}{l}82^{\circ} \text { detection } \\
\text { angle, } 0-10 \mathrm{~m} \\
\text { detection range }\end{array}$ & - & $\begin{array}{l}\text { Associated with posi- } \\
\text { tioning and set-up }\end{array}$ \\
\hline Window Opening & $\begin{array}{l}\text { Magnetic Reed Switch - } \\
\text { state data logger (Eltek } \\
\text { GS34 or Lascar USB-5) }\end{array}$ & 0-I (open/closed) & - & $\begin{array}{l}\text { Associated with posi- } \\
\text { tioning and set-up }\end{array}$ \\
\hline
\end{tabular}


$\mathrm{CO}_{2}, \mathrm{PM}_{10}$ and $\mathrm{PM}_{2.5}$ along with occupancy state in bedrooms and living rooms (as detected by PIR sensors) and operation of windows (as captured by contact sensors) at 5-min intervals.

The data analysis examined the impact of the lockdown at two scales. The first fortnight of lockdown was compared with the fortnight prior, to quantify the immediate impact of the lockdown. Then, to get a broader understanding of the overall effect, a 3-month period midlockdown has been compared with a 3-month period in the previous year with similar weather conditions.

\section{Window operation analysis and modelling}

Prior to modelling the occupant interactions with windows, three metrics are used to capture the key characteristics of window operation by occupants in pre-lockdown and lockdown periods:

- Overall fraction of open state [-]

- Median open state duration [h]

- Opening rate in occupied intervals $\left[\mathrm{h}^{-1}\right]$

Addressing the state of windows, the first metric gives an overall picture of window

Table 2. The parameters examined to explain occupants' operation of windows.

\begin{tabular}{lll}
\hline Parameter & Symbol & Unit \\
\hline Indoor air temperature & $\mathrm{T}_{\text {in }}$ & ${ }^{\circ} \mathrm{C}$ \\
Outdoor air temperature & $\mathrm{T}_{\text {out }}$ & \\
Indoor relative humidity & $\mathrm{RH}_{\text {in }}$ & $\%$ \\
Outdoor relative humidity & $\mathrm{RH}_{\text {out }}$ & \\
Indoor $\mathrm{PM}_{2.5}$ level & ${\mathrm{PM} 2.5_{\text {in }}}$ & $\mu \mathrm{g} / \mathrm{m}^{3}$ \\
Indoor $\mathrm{PM}_{10}$ level & $\mathrm{PMIO}_{\text {in }}$ & \\
Outdoor $\mathrm{PM}_{2.5}$ level & ${\mathrm{PM} 2.5_{\text {out }}}$ & \\
Outdoor $\mathrm{PM}_{10}$ level & $\mathrm{PMI0}_{\text {out }}$ & \\
Indoor $\mathrm{CO}_{2}$ concentration & $\mathrm{CO}_{2, \text { in }}$ & $\mathrm{PPm}$ \\
Indoor total volatile & $\mathrm{TVO}_{\text {in }}$ & \\
\multicolumn{1}{c}{ organic compound } & & \\
\hline
\end{tabular}

openings and the second metric captures the typical duration of window opening instances. The third metric, however, encapsulates the opening actions and normalises them based on the duration of time when the room is occupied. $^{22}$

To develop models of occupant behaviour, the authors examined a range of measured indoor and outdoor parameters in terms of their potential to explain the monitored window operation (Table 2). Thereby, to minimise multicollinearity, a pairwise correlation check was conducted as an initial variable selection process. Subsequently, using the noncorrelated independent variables, logistic regression models of window opening and closing actions for all monitored windows were developed. This process involved estimating the regression coefficient $\left(\beta_{1}\right)$ and intercept $\left(\beta_{0}\right)$ in equation (1), where $P$ is the probability of opening or closing windows and $\mathrm{x}$ refers to different independent variables. P-value was used to judge the statistical significance of each variable at 0.05 significance level.

$$
P=\frac{\exp \left(\beta_{0}+\beta_{1} x\right)}{1+\exp \left(\beta_{0}+\beta_{1} x\right)}
$$

\section{The calibrated building model}

The authors modelled one of the monitored flats (flat 4) in the building simulation tool EnergyPlus 9.4. This is a $50.8 \mathrm{~m}^{2}$ one-bedroom flat with one-sided ventilation through two eastfacing windows in the bedroom and living room (see Figure 1). The building envelope is highly insulated with U-Values of $0.18,0.92,0.13$ and $0.12\left[\mathrm{~W} / \mathrm{m}^{2} . \mathrm{k}\right]$ for the walls, windows, ceilings and floors respectively. The building is also equipped with mechanical ventilation with heat recovery (MVHR). In the simulation test case number 7 (see next section), MVHR operates 


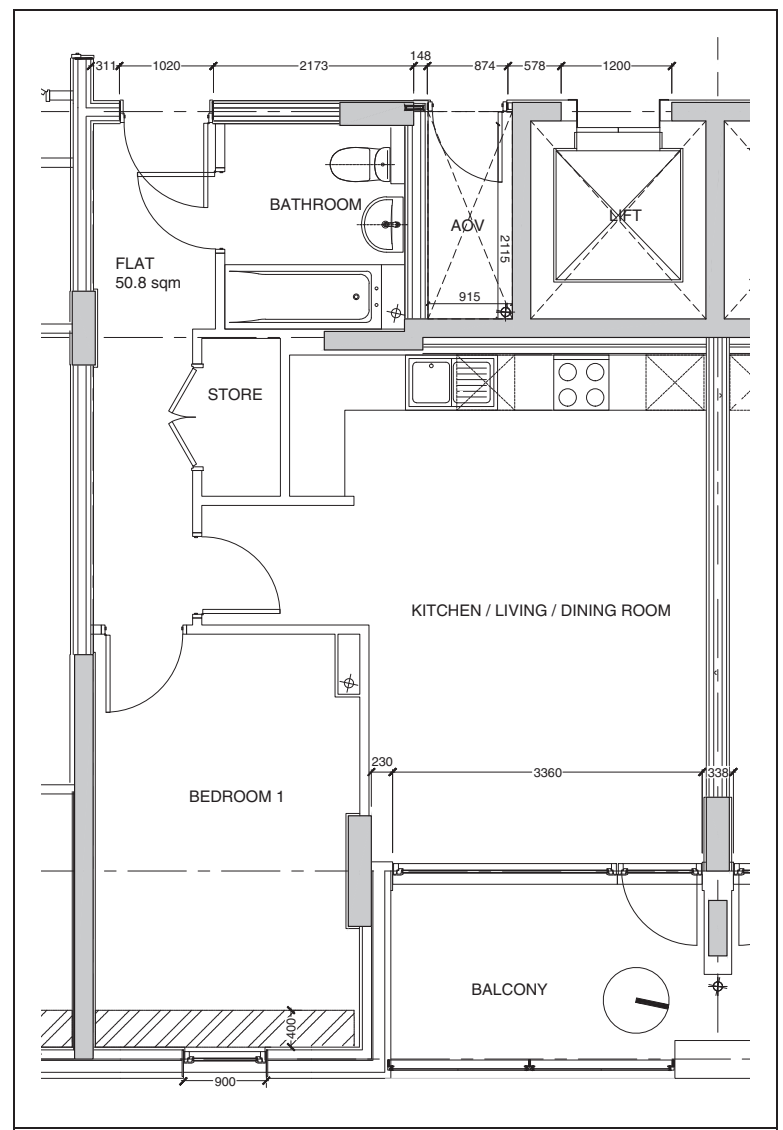

Figure I. The floor plan of the modelled flat.

night and day in the heating season, providing $7 \mathrm{~L} /$ s.person outdoor air with a sensible heat recovery effectiveness of 0.75 .

For the purpose of current study, the EnergyPlus building model is mainly indented to estimate indoor $\mathrm{CO}_{2}$ concentrations under different ventilation scenarios. The model comprises of five thermal zones including bedroom, living room, store, corridor and bathroom. The airflow through the windows and across the zones is simulated using the multi-zone airflow network model of EnergyPlus. The walls, floor and ceiling, adjacent to the neighbouring flats, are assumed to be adiabatic.

Whereas previous efforts have predominantly relied on energy use data or monitored indoor temperatures to calibrate building thermal performance models (e.g.), ${ }^{2,24}$ the present study uses monitored $\mathrm{CO}_{2}$ concentrations directly to calibrate a building model tailored for indoor air quality assessments. More specifically, the following steps were carried out to prepare an 
initial thermal performance model of the flat for calibration:

- The calibration period was set to 15 July to 31 October 2019, during which time the MVHR system was not operating in the flat.

- Thermal properties of the building fabric elements and internal heat gain sources (other than occupants) were defined based on the best information available to the modellers.

- Monitored data on occupancy, window states and on-site outdoor $\mathrm{CO}_{2}$ concentration from the calibration period were incorporated into the EnergyPlus model to reduce the number of unknown parameters in the underdetermined calibration problem.

- Hourly outdoor environmental data from the same period (including air temperature, air relative humidity, global, diffuse and direct irradiance along with wind speed and direction) were used to create real-year weather data for the purpose of model calibration.

To produce a more reliable building model, the key input parameters governing the air flow model and $\mathrm{CO}_{2}$ generation were subjected to calibration. These were opening factors for the open state of windows and interior doors, air mass flow through closed openings, and occupants' activity level and $\mathrm{CO}_{2}$ generation rate. As given in Table 3, for the initial model, the opening factors and air mass flow through closed openings were set based on the values in DesignBuilder software library for mediumtight openings and cracks. The initial activity level value was assumed based on the modeller's estimation, and the initial occupant carbon dioxide generation rate was set to EnergyPlus default value. Subsequently, an iterative process of minimizing the errors in the predicted $\mathrm{CO}_{2}$ concentrations was conducted. Two error metrics, namely Mean Bias Error (MBE) and Root Mean Square Error (RMSE) captured the model predictive potential in the calibration period. The authors also largely benefitted from visualizations of model predictions in the process, so that the resulting calibrated model could better predict the patterns of $\mathrm{CO}_{2}$ decay and build-up in different rooms.

Figure 2 illustrates a 2-day section of the estimated $\mathrm{CO}_{2}$ concentrations in the living room obtained from the initial and calibrated building models compared with the monitored concentrations. Table 3 lists the calibration variables and their values in the initial and calibrated models and Table 4 gives the obtained error metrics for the estimated $\mathrm{CO}_{2}$ concentrations by the initial and calibrated models in the bedroom and the living room.

\section{Building simulation test cases}

Using the calibrated thermal performance model, the authors examined a number of occupancy and ventilation scenarios to get a better picture of the impact of lockdown on IAQ and the mitigating potential of different ventilation strategies. To this end, two occupancy patterns were considered, namely a common home occupancy schedule before the outbreak (referred to

Table 3. Model inputs subjected to calibration.

\begin{tabular}{lll}
\hline Input parameters & Initial model & Calibrated model \\
\hline Bedroom closed window air mass flow coefficient $[\mathrm{kg} / \mathrm{s.m}]$ & 0.0001 & 0.0005 \\
Living room closed window air mass flow coefficient $[\mathrm{kg} / \mathrm{s.m}]$ & 0.0001 & 0.02 \\
Bedroom window width factor for open state $[-]$ & 0.05 & 1 \\
Living room window width factor for open state $[-]$ & 0.05 & 0.6 \\
Corridor door width factor for open state $[-]$ & 0.025 & 1 \\
Living room occupant activity level [W/person] & 99 & 115 \\
Occupant carbon dioxide generation rate $\left[\mathrm{m}^{3} / \mathrm{s}-\mathrm{W}\right]$ & $3.82 \mathrm{E}-08$ & $6.00 \mathrm{E}-08$ \\
\hline
\end{tabular}




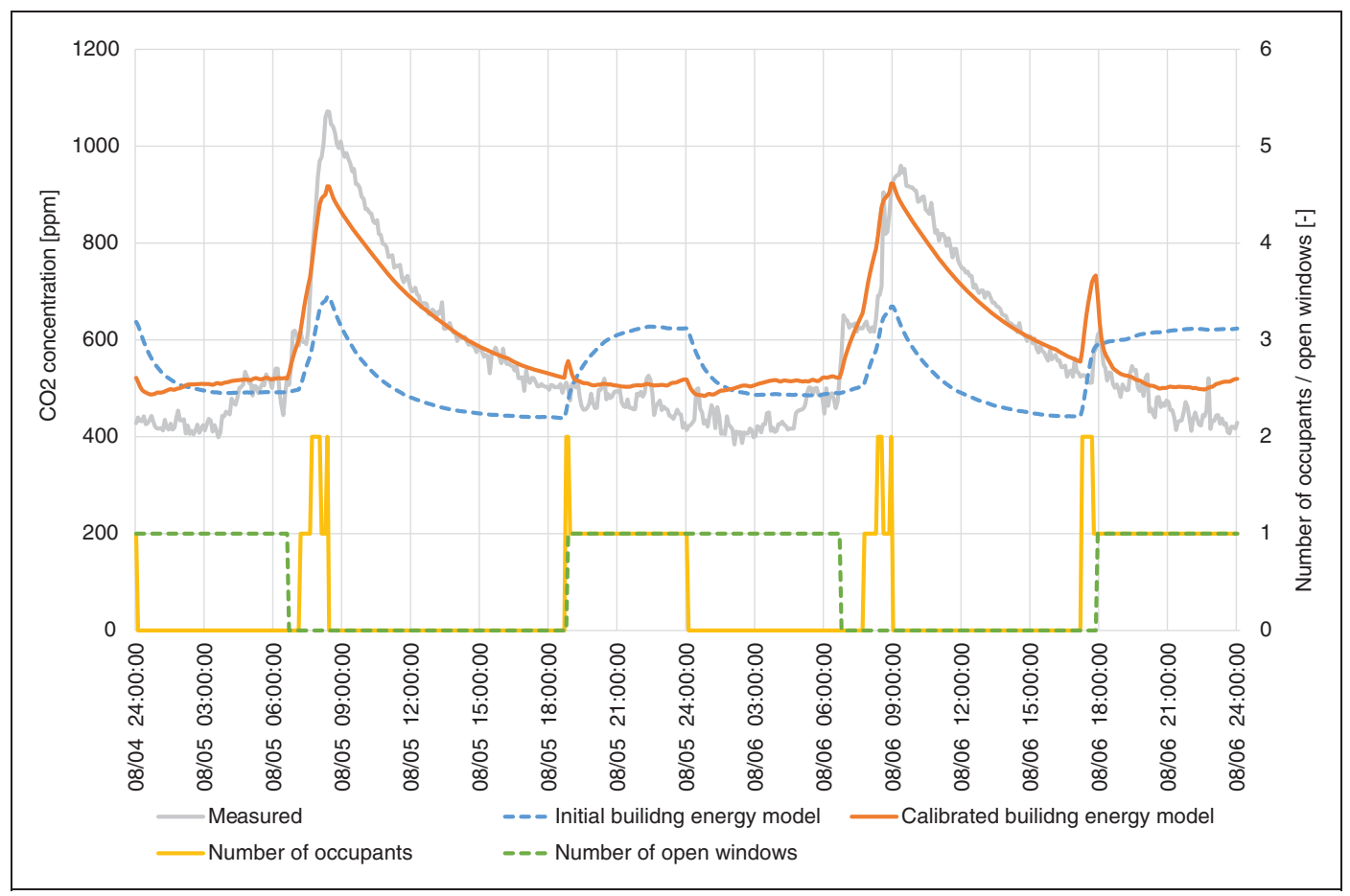

Figure 2. A two-day section of predicted living room $\mathrm{CO}_{2}$ concentrations by the initial and calibrated building energy models in comparison with the measured values.

Table 4. Errors from the initial and calibrated models.

\begin{tabular}{lll}
\hline Error metrics & $\begin{array}{l}\text { Initial } \\
\text { model }\end{array}$ & $\begin{array}{l}\text { Calibrated } \\
\text { model }\end{array}$ \\
\hline Bedroom MBE [Ppm] & -245 & 60 \\
Living room MBE [Ppm] & -86 & -42 \\
Bedroom RMSE [Ppm] & 511 & 318 \\
Living room RMSE [Ppm] & 270 & 189 \\
\hline
\end{tabular}

as normal occupancy, in this case involving 2 occupants in the flat from 18:00 to 8:00 $(+1)$ on weekdays and from 13:00 to $10: 00(+1)$ on weekends), and a constant full occupancy (referred to as lockdown occupancy). In terms of ventilation, a worst case scenario of no window operation, two effective patterns of natural ventilation in free-running and heating seasons, and use of MVHR system were studied.
Thus, the simulation-based study involved the following simulation test cases:

1. Non-heating season, normal occupancy, no window operation or mechanical ventilation

2. Non-heating season, lockdown occupancy, no window operation or mechanical ventilation

3. Non-heating season, lockdown occupancy, bedroom window open for 1 hour in the morning, living room window open in waking hours

4. Heating season, normal occupancy, no window operation or mechanical ventilation

5. Heating season, lockdown occupancy, no window operation or mechanical ventilation

6. Heating season, lockdown occupancy, 1 to 2 windows open for $15 \mathrm{~min}$ every 4 waking hours 
7. Heating season, lockdown occupancy, MVHR providing $7 \mathrm{~L} /$ s.person outdoor air.

\section{Building performance metrics}

To capture the occupants' exposure to relatively high levels of $\mathrm{CO}_{2}$ concentration, the following building performance metrics were obtained for each simulation test:

- Peak $\mathrm{CO}_{2}$ concentration in each room [ppm]

- Sleeping time $\mathrm{CO}_{2}$ above 2500 [\%]: This is the percentage of sleeping hours in the bedroom with $\mathrm{CO}_{2}$ concentrations above $2500 \mathrm{ppm}$.

- Active time $\mathrm{CO}_{2}$ above 2500 [\%]: This is the percentage of occupied hours in the living room with $\mathrm{CO}_{2}$ concentrations above $2500 \mathrm{ppm}$.

The threshold of $2500 \mathrm{ppm}$ is set based on the aforementioned study by Satish et al. ${ }^{15}$ on the impact of low to moderate $\mathrm{CO}_{2}$ concentrations on human decision-making performance. While, for bedrooms, Mishra et al., ${ }^{14}$ as an example, suggest a $\mathrm{CO}_{2}$ threshold close to $1150 \mathrm{ppm}$ (beyond which sleep of healthy young adults may start getting compromised), for the purpose of the current study we utilized a single threshold for both rooms. Furthermore, to study the implications of different ventilation strategies for building energy use, the building heating energy load in $\mathrm{kWh} / \mathrm{m}^{2}$ was estimated for each heating season test case. A heating setpoint of $22^{\circ} \mathrm{C}$ has been used when calculating the heating energy load.

\section{Results and discussion}

\section{Monitored air quality and window operation}

The monitored data - not surprisingly revealed a substantial increase of occupancy levels in the studied flats especially on weekdays, as shown in Figure 3. Nonetheless, rather unexpectedly, occupants have relied less on natural ventilation (Figure 4). Table 5 suggests that during the lockdown period occupants have opened the windows for far shorter periods of time (a mean value of 2.9 versus $4.9 \mathrm{~h}$ ) resulting in a lower overall fraction of open window state $(21.7 \%$ versus $32.3 \%)$. While this can be partly explained by the slightly higher outdoor temperatures in the selected pre-lockdown period, the data from the fortnights around the lockdown (with very similar weather conditions) confirms the decreased level of night-time natural

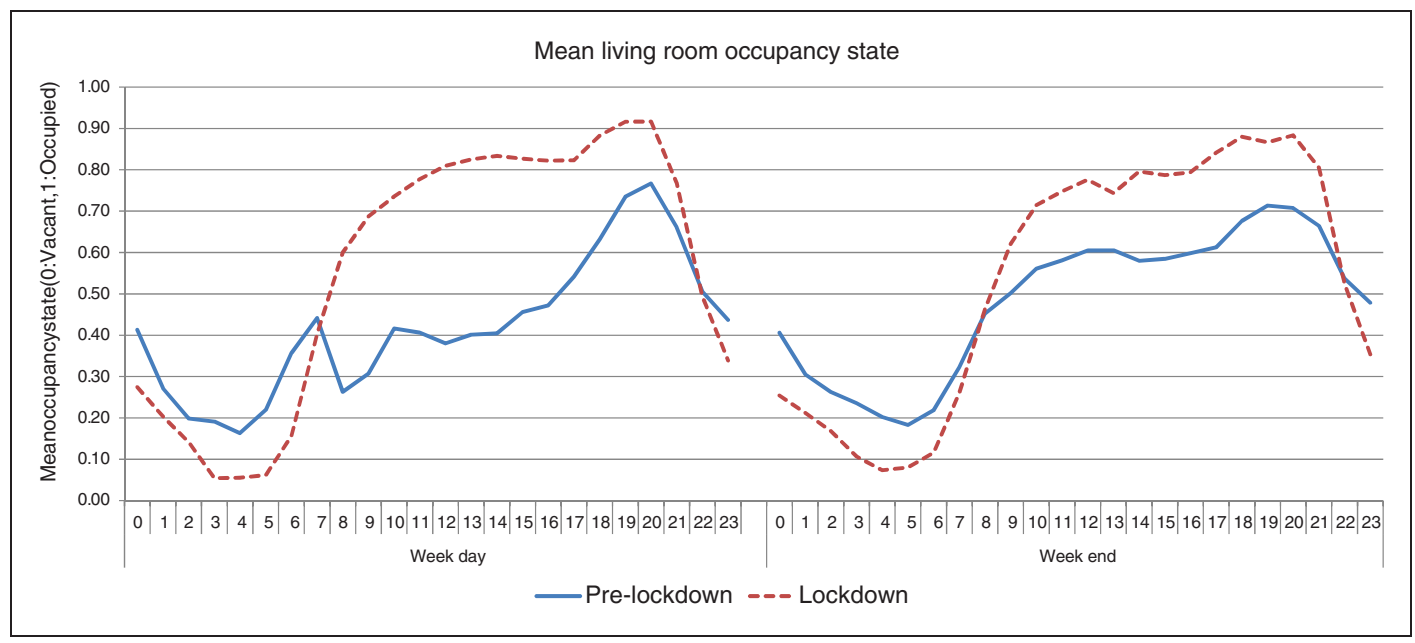

Figure 3. Mean living room occupancy state on weekdays and weekends of two 3-month periods prior to and during lockdown. 


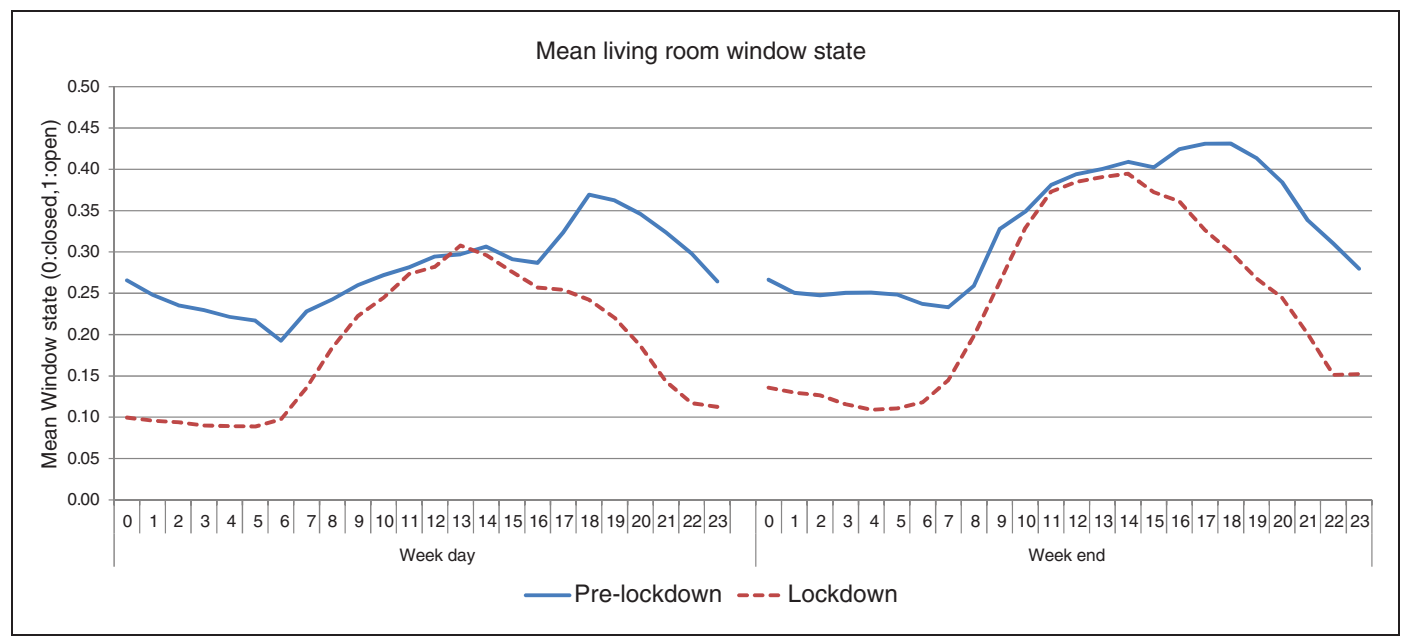

Figure 4. Mean living room window state on weekdays and weekends of two 3-month periods prior to and during lockdown.

Table 5. Window operation metrics.

\begin{tabular}{|c|c|c|c|c|c|c|}
\hline \multirow{2}{*}{$\begin{array}{l}\text { Window } \\
\text { number }\end{array}$} & \multicolumn{2}{|c|}{ Overall fraction of open state [\%] } & \multicolumn{2}{|c|}{ Median opening duration $[\mathrm{h}]$} & \multicolumn{2}{|c|}{ Opening action rate $\left[\mathrm{h}^{-1}\right]$} \\
\hline & Pre-lockdown & Lockdown & Pre-lockdown & Lockdown & Pre-lockdown & Lockdown \\
\hline Flat I WI & $12.9 \%$ & $6.6 \%$ & 11.8 & 8.6 & 0.007 & 0.008 \\
\hline Flat I W2 & $39.8 \%$ & $24.2 \%$ & 12.0 & 10.7 & 0.032 & 0.035 \\
\hline Flat $2 \mathrm{WI}$ & $53.6 \%$ & $13.5 \%$ & 0.1 & 0.1 & 0.061 & 0.105 \\
\hline Flat 2 W2 & $67.6 \%$ & $39.5 \%$ & 0.7 & 0.6 & 0.109 & 0.101 \\
\hline Flat $3 \mathrm{WI}$ & $21.1 \%$ & $11.1 \%$ & 2.3 & 0.8 & 0.062 & 0.082 \\
\hline Flat $3 \mathrm{~W} 2$ & $42.3 \%$ & $16.0 \%$ & 2.9 & 1.3 & 0.057 & 0.094 \\
\hline Flat $4 \mathrm{~W}$ & $42.9 \%$ & $42.3 \%$ & 5.7 & 0.5 & 0.105 & 0.178 \\
\hline Flat $5 \mathrm{WI}$ & $3.2 \%$ & $4.0 \%$ & 0.5 & 0.3 & 0.057 & 0.075 \\
\hline Flat $5 \mathrm{~W} 2$ & $47.3 \%$ & $11.9 \%$ & 12.8 & 2.1 & 0.029 & 0.027 \\
\hline Flat 5 W3 & $54.1 \%$ & $31.5 \%$ & 12.3 & 3.0 & 0.037 & 0.043 \\
\hline Flat $6 \mathrm{~W}$ & $11.3 \%$ & $14.5 \%$ & 2.3 & 1.8 & 0.042 & 0.078 \\
\hline Flat $7 \mathrm{~W}$ & $19.7 \%$ & $48.4 \%$ & 3.2 & 3.2 & 0.141 & 0.090 \\
\hline Flat $8 \mathrm{WI}$ & $2.6 \%$ & $1.0 \%$ & 0.7 & 6.0 & 0.002 & 0.003 \\
\hline Flat $8 \mathrm{~W} 2$ & $34.3 \%$ & $38.7 \%$ & 1.7 & 1.6 & 0.117 & 0.179 \\
\hline Mean & $32.3 \%$ & $21.7 \%$ & 4.9 & 2.9 & 0.061 & 0.078 \\
\hline Standard deviation & $20.6 \%$ & $15.6 \%$ & 5.0 & 3.3 & 0.042 & 0.054 \\
\hline
\end{tabular}

ventilation by occupants. The outcome of this higher occupancy and lower natural ventilation can be clearly seen in Figure 5, which shows that the living room median $\mathrm{CO}_{2}$ concentration has increased up to $300 \mathrm{ppm}$ at specific hours. Figure 6 also reveals that, despite the lower outdoor $\mathrm{PM}_{10}$ concentrations on weekdays during the lockdown, indoor $\mathrm{PM}_{10}$ concentrations rose 


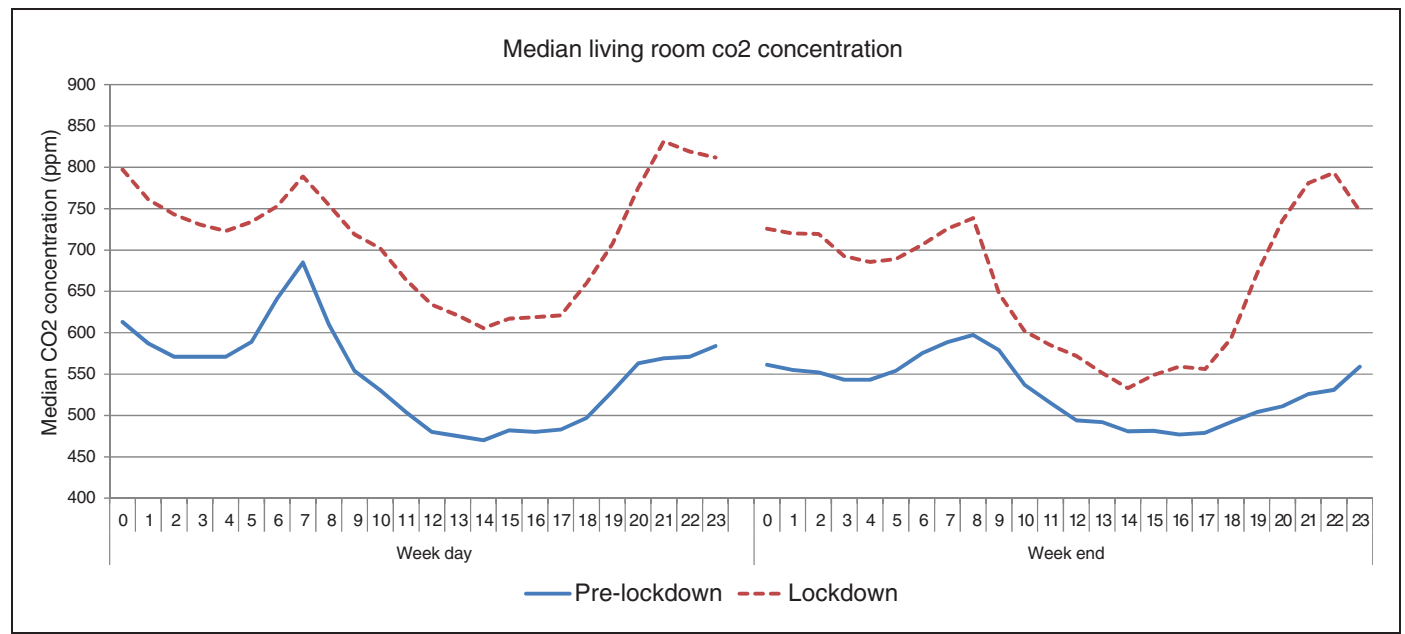

Figure 5. Median living room $\mathrm{CO}_{2}$ concentration on weekdays and weekends of two 3-month periods prior to and during lockdown.

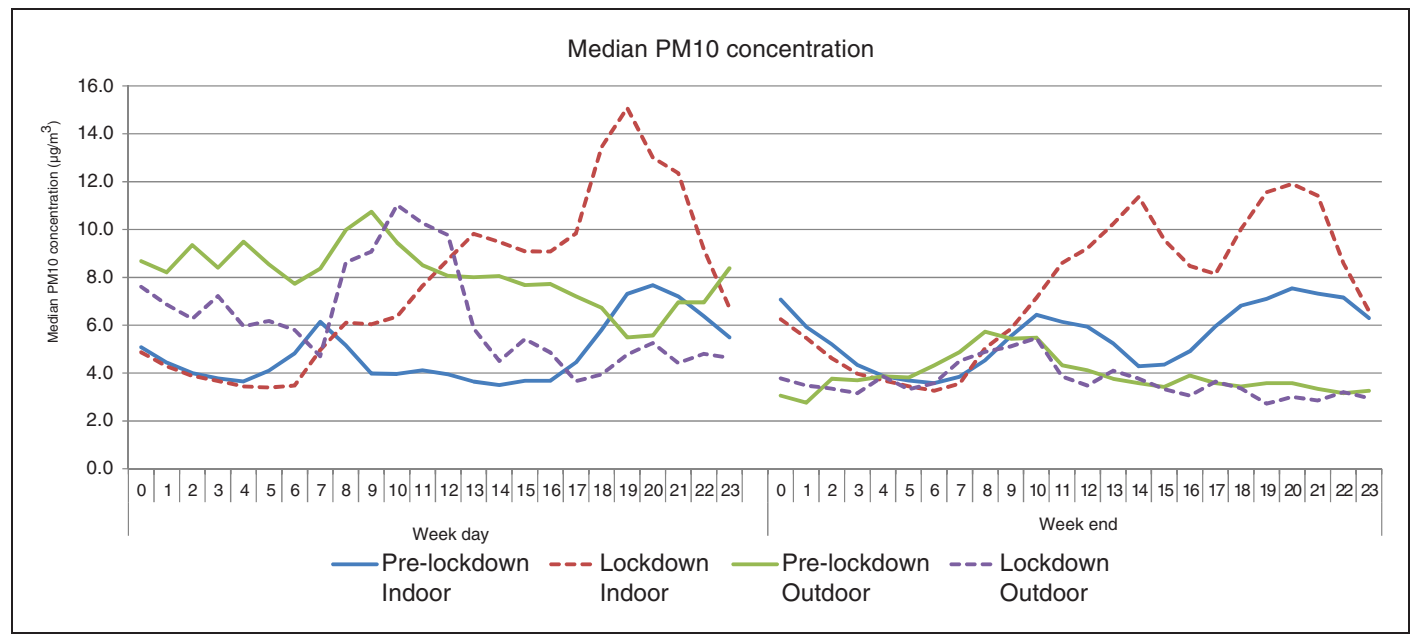

Figure 6. Median indoor and outdoor $\mathrm{PM}_{10}$ concentration on weekdays and weekends of two 3-month periods prior to and during lockdown.

on weekdays (as well as on weekends) in this period.

\section{Window operation driving factors}

Before identifying the main driving environmental factors behind the operation of windows by occupants, the correlation analysis detected highly correlated parameters of $\mathrm{T}_{\text {in }}$ and $\mathrm{T}_{\text {out }}$, $\mathrm{RH}_{\text {in }}$ and $\mathrm{RH}_{\text {out }}, \mathrm{PM}_{2.5 \text {,in }}$ and $\mathrm{PM}_{10 \text {,in }}$, and $\mathrm{PM}_{2.5 \text {,out }}$ and $\mathrm{PM}_{10 \text {,out }}$. Therefore, to minimise multicollinearity, the subsequent variable selection procedure (based on statistical significant test) was applied to a subset of measured parameters including $\mathrm{T}_{\text {in }}, \mathrm{RH}_{\text {in }}, \mathrm{CO}_{2 \text {,in }}, \mathrm{PM} 2.5_{\text {out }}$, $\mathrm{PM}_{2.5 \mathrm{in}}$, and $\mathrm{TVOC}_{\mathrm{in}}$. 
Table 6 summarizes the results of the statistical significance test. It gives the fraction of 14 monitored windows in 8 studied flats, where each independent variable is statistically significant to explain the opening and closing actions. These fractions clearly suggest that indoor temperature is the main driving factor for opening and closing windows in both pre-lockdown and lockdown periods. In contrast, the variables representing indoor air quality do not explain the operation of windows in the majority of flats. Given the rather similar significance fractions in the pre-lockdown and lockdown periods, one can argue that the thermal comfort-driven

Table 6. The statistical significance fraction of different environmental parameters to explain window opening and closing actions across the studied flats.

\begin{tabular}{llllll}
\hline & \multicolumn{2}{l}{ Significance fraction for window opening } & & \multicolumn{2}{c}{ Significance fraction for window closing } \\
\cline { 2 - 3 } Independent variable & Pre-lockdown & Lockdown & & Pre-lockdown & Lockdown \\
\hline $\mathrm{T}_{\text {in }}$ & $78.6 \%$ & $78.6 \%$ & $57.1 \%$ & $71.4 \%$ \\
$\mathrm{RH}_{\text {in }}$ & $21.4 \%$ & $50.0 \%$ & & $28.6 \%$ & $7.1 \%$ \\
$\mathrm{CO}_{\text {in }}$ & $42.9 \%$ & $42.9 \%$ & & $35.7 \%$ & $35.7 \%$ \\
$\mathrm{PM} 2.5_{\text {in }}$ & $35.7 \%$ & $35.7 \%$ & & $35.7 \%$ & $14.3 \%$ \\
$\mathrm{PM} 2.5_{\text {out }}$ & $21.4 \%$ & $21.4 \%$ & & $28.6 \%$ & $14.3 \%$ \\
$\mathrm{TVOC}_{\text {in }}$ & $21.4 \%$ & $21.4 \%$ & $28.6 \%$ & $14.3 \%$ \\
\hline
\end{tabular}

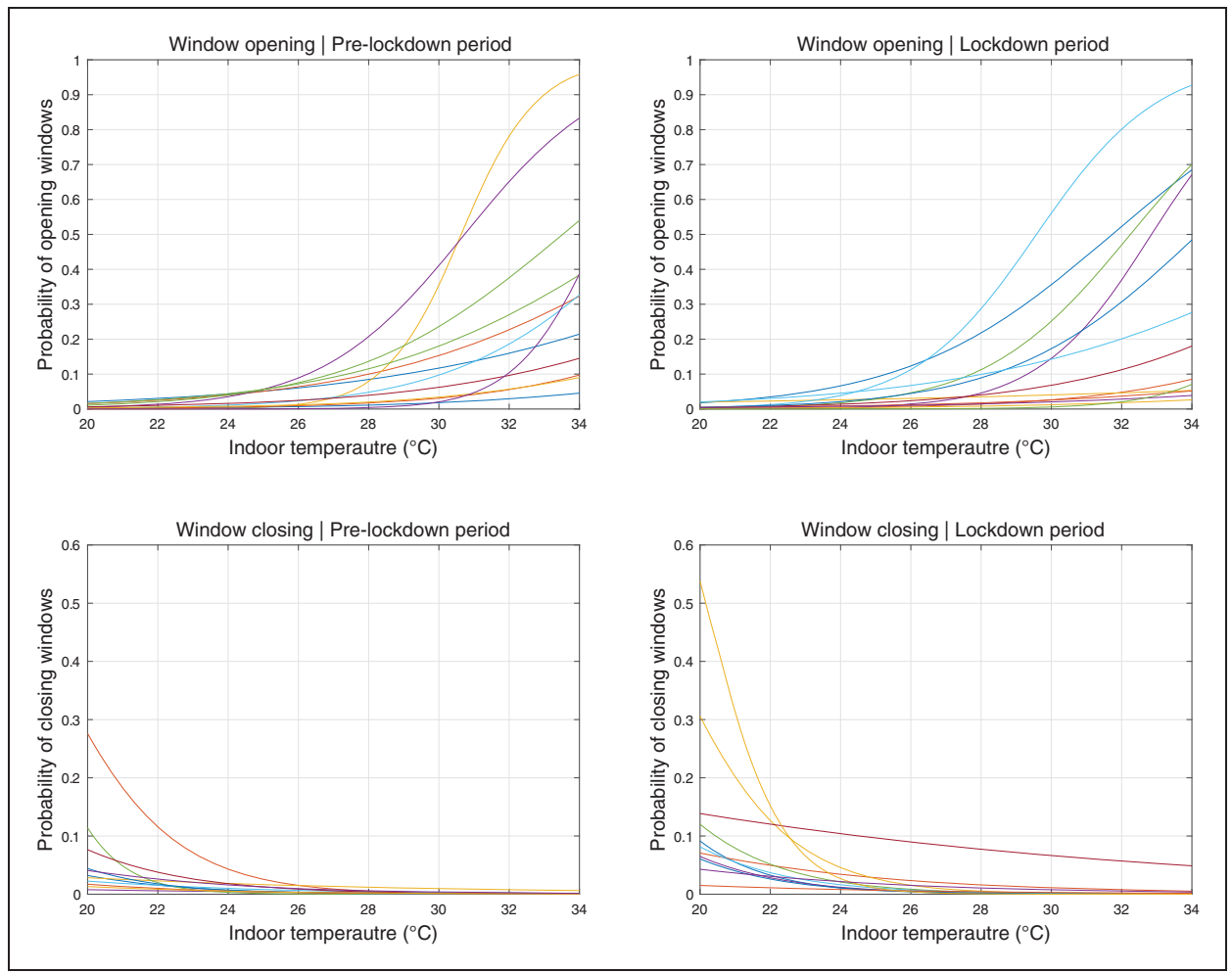

Figure 7. Window opening and closing models. 
window operation behaviour of occupants has not changed during the lockdown.

\section{Window operation models}

Given the dominance of indoor temperature to explain window operation across the monitored flats, for the purpose of the current study, only indoor temperature-based univariate models of window opening and closing actions are presented in Figure 7. Moreover, the estimated coefficients of these models are given in
Table 7. These models give the probability of opening and closing windows at different indoor temperatures in the studied flats. As can be seen clearly in Figure 7, the window opening and closing trend remains the same in the pre-lockdown and lockdown periods: People are more likely to open windows at higher indoor temperatures and close them at lower indoor temperatures. However, the resulting models suggest that at any given indoor temperature, it is slightly more likely for occupants to close the windows during the lockdown.

Table 7. The estimated coefficients for univariate window opening and closing models.

\begin{tabular}{|c|c|c|c|c|c|c|c|c|c|}
\hline \multirow[b]{3}{*}{ Window } & \multirow[b]{3}{*}{ Coef. } & \multicolumn{4}{|c|}{ Opening model } & \multicolumn{4}{|c|}{ Closing model } \\
\hline & & \multicolumn{2}{|c|}{ Pre-lockdown } & \multicolumn{2}{|l|}{ lockdown } & \multicolumn{2}{|c|}{ Pre-lockdown } & \multicolumn{2}{|l|}{ lockdown } \\
\hline & & Estimate & $\mathrm{P}$-value & Estimate & $\mathrm{P}$-value & Estimate & $\mathrm{P}$-value & Estimate & $\mathrm{P}$-value \\
\hline \multirow[t]{2}{*}{ Flat I WI } & b0 & -28.54 & $9.49 \mathrm{E}-26$ & -20.46 & $2.20 \mathrm{E}-07$ & 0.39 & $9.19 \mathrm{E}-01$ & -3.14 & 4.07E-0I \\
\hline & bl & 0.93 & $1.79 E-17$ & 0.62 & $4.93 \mathrm{E}-04$ & -0.24 & I.26E-0| & -0.08 & $6.61 \mathrm{IE}-0 \mathrm{I}$ \\
\hline \multirow[t]{2}{*}{ Flat I W2 } & b0 & -4.94 & $8.64 \mathrm{E}-04$ & -7.01 & $1.43 \mathrm{E}-04$ & -2.08 & $5.14 \mathrm{E}-02$ & -1.94 & $2.84 \mathrm{E}-0 \mathrm{I}$ \\
\hline & bl & -0.02 & $7.96 \mathrm{E}-0 \mathrm{I}$ & 0.08 & $3.98 \mathrm{E}-0 \mathrm{I}$ & -0.14 & $5.65 \mathrm{E}-03$ & -0.13 & I.27E-0 | \\
\hline \multirow[t]{2}{*}{ Flat $2 \mathrm{WI}$} & bo & $-|5.1|$ & $6.06 \mathrm{E}-17$ & -15.64 & $1.91 \mathrm{E}-26$ & 16.47 & $4.47 E-18$ & 10.29 & $8.21 E-16$ \\
\hline & bl & 0.49 & $1.28 \mathrm{E}-09$ & 0.49 & $8.7 I E-I 5$ & -0.93 & $2.46 \mathrm{E}-27$ & -0.56 & I.54E-24 \\
\hline \multirow[t]{2}{*}{ Flat 2 W2 } & bo & -9.34 & $6.35 E-16$ & -17.03 & $2.64 \mathrm{E}-35$ & 0.34 & 7.37E-0I & 6.05 & $3.88 \mathrm{E}-05$ \\
\hline & bl & 0.26 & $2.76 \mathrm{E}-07$ & 0.58 & $3.68 \mathrm{E}-22$ & -0.21 & $3.90 \mathrm{E}-06$ & -0.44 & $9.37 E-12$ \\
\hline \multirow[t]{2}{*}{ Flat $3 \mathrm{WI}$} & bo & -13.53 & $3.76 \mathrm{E}-33$ & -10.89 & $1.01 E-16$ & 5.00 & 6.47E-04 & 7.26 & $2.83 E-06$ \\
\hline & bl & 0.38 & $8.39 \mathrm{E}-16$ & 0.28 & $1.46 \mathrm{E}-06$ & -0.37 & $1.18 \mathrm{E}-09$ & -0.46 & I.74E- II \\
\hline \multirow[t]{2}{*}{ Flat $3 \mathrm{~W} 2$} & bo & -9.79 & $1.79 E-16$ & -12.85 & $6.17 \mathrm{E}-24$ & 6.44 & $2.77 E-06$ & 5.95 & $9.64 \mathrm{E}-05$ \\
\hline & bl & 0.24 & $5.30 \mathrm{E}-06$ & 0.38 & |.04E-| | & -0.48 & $4.33 \mathrm{E}-15$ & -0.42 & $6.58 \mathrm{E}-10$ \\
\hline \multirow[t]{2}{*}{ Flat $4 \mathrm{~W}$} & b0 & -7.44 & $1.25 \mathrm{E}-16$ & -10.85 & 2.47E-28 & 4.13 & I.44E-04 & 8.67 & I.53E-20 \\
\hline & bl & 0.18 & $5.06 \mathrm{E}-06$ & 0.34 & $5.53 \mathrm{E}-\mathrm{I} 4$ & -0.38 & $1.83 \mathrm{E}-14$ & -0.55 & I.20E-36 \\
\hline \multirow[t]{2}{*}{ Flat $5 \mathrm{WI}$} & bo & -11.09 & $7.25 \mathrm{E}-17$ & -9.14 & $5.17 \mathrm{E}-16$ & -1.74 & $\mid .28 \mathrm{E}-0 \mathrm{|}$ & -0.19 & $8.05 \mathrm{E}-0 \mathrm{I}$ \\
\hline & bl & 0.24 & $4.54 \mathrm{E}-06$ & 0.18 & $1.72 \mathrm{E}-04$ & -0.04 & $3.68 \mathrm{E}-0 \mathrm{I}$ & -0.08 & $1.68 \mathrm{E}-02$ \\
\hline \multirow[t]{2}{*}{ Flat 5 W2 } & bo & $-|2.5|$ & I.29E-09 & -10.29 & $9.54 \mathrm{E}-08$ & 1.91 & $\mid .52 \mathrm{E}-0 \mathrm{|}$ & 6.10 & $2.33 \mathrm{E}-04$ \\
\hline & bl & 0.30 & $3.13 \mathrm{E}-04$ & 0.20 & $2.03 \mathrm{E}-02$ & -0.30 & $2.27 \mathrm{E}-07$ & -0.44 & $2.67 \mathrm{E}-09$ \\
\hline \multirow[t]{2}{*}{ Flat $5 \mathrm{~W} 3$} & bo & -11.08 & $8.83 \mathrm{E}-10$ & -8.85 & $5.08 \mathrm{E}-09$ & 0.32 & $8.00 \mathrm{E}-0 \mathrm{I}$ & -0.94 & $3.74 \mathrm{E}-0 \mathrm{I}$ \\
\hline & bl & 0.26 & $4.90 \mathrm{E}-04$ & 0.17 & $1.36 \mathrm{E}-02$ & -0.23 & I.7IE-05 & -0.16 & $7.18 \mathrm{E}-04$ \\
\hline \multirow[t]{2}{*}{ Flat $6 \mathrm{~W}$} & b0 & -8.31 & $3.55 \mathrm{E}-07$ & -12.89 & $2.93 \mathrm{E}-32$ & 9.72 & I.89E-04 & 1.26 & $2.54 \mathrm{E}-0 \mathrm{I}$ \\
\hline & bl & 0.11 & 6.67E-02 & 0.31 & $1.08 \mathrm{E}-14$ & -0.53 & I.79E-07 & -0.19 & I.72E-05 \\
\hline \multirow[t]{2}{*}{ Flat $7 \mathrm{~W}$} & bo & -9.02 & $1.98 \mathrm{E}-68$ & -5.37 & $2.39 \mathrm{E}-46$ & -1.34 & $1.90 \mathrm{E}-02$ & -3.98 & $1.80 E-13$ \\
\hline & bl & 0.24 & 4.24E-32 & 0.07 & $3.80 \mathrm{E}-08$ & -0.11 & $1.06 \mathrm{E}-05$ & -0.03 & $2.56 \mathrm{E}-0 \mathrm{I}$ \\
\hline \multirow[t]{2}{*}{ Flat $8 \mathrm{WI}$} & bo & -29.33 & I.79E-03 & -24.33 & I.I2E-03 & 16.77 & $3.47 \mathrm{E}-0 \mathrm{I}$ & 18.88 & 4. $15 \mathrm{E}-02$ \\
\hline & bl & 0.85 & $1.73 \mathrm{E}-02$ & 0.64 & $2.26 \mathrm{E}-02$ & -0.83 & $2.4 \mid \mathrm{E}-0 \mathrm{I}$ & -0.94 & $1.61 \mathrm{IE}-02$ \\
\hline \multirow[t]{2}{*}{ Flat 8 W2 } & b0 & -11.19 & I.72E-39 & -8.04 & $1.94 \mathrm{E}-28$ & 1.69 & $1.88 \mathrm{E}-02$ & 0.43 & $5.44 \mathrm{E}-0 \mathrm{I}$ \\
\hline & bl & 0.33 & I.32E-18 & 0.21 & $1.43 \mathrm{E}-11$ & -0.24 & $1.67 \mathrm{E}-13$ & -0.18 & I.07E-08 \\
\hline
\end{tabular}




\section{Simulation-based investigations}

Firstly, considering the worst-case scenarios, the simulation results suggest that the extended occupancy hours during a lockdown can significantly increase occupants' exposure to $\mathrm{CO}_{2}$ (see Table 8, tests number 1, 2, 4 and 5). For example, during a lockdown in the heating season, occupants could face $\mathrm{CO}_{2}$ concentrations of above $2500 \mathrm{ppm}$ for almost $90 \%$ of the time that they spend in the living room, compared to only $33 \%$ with a normal occupancy pattern. As illustrated in Figures 8 and 9, the impact of lockdown occupancy on $\mathrm{CO}_{2}$ levels can be seen clearly in both the living room and bedroom, even though the bedroom occupancy patterns are assumed to be identical in the normal and lockdown scenarios.

Secondly, as can be seen in Table 8 and Figure 10, the selected natural ventilation strategy for a lockdown during a non-heating season (test number 3 ) seems to be very effective to reduce $\mathrm{CO}_{2}$. In the living room, the $\mathrm{CO}_{2}$ concentrations never exceed the $2500 \mathrm{ppm}$ threshold. In the bedroom, this happens for less than 2 percent of occupied time, even though the windows in both the bedroom and living room are assumed to be closed during the sleeping time.

Thirdly, although the natural ventilation pattern suggested for the heating season relies on much shorter window openings (test number 6), it manages to noticeably reduce the $\mathrm{CO}_{2}$ levels (see Table 8 and Figure 11). That is, the living room $\mathrm{CO}_{2}$ concentrations never reach the threshold of $2500 \mathrm{ppm}$ and the bedroom $\mathrm{CO}_{2}$ levels exceed this level for only $29 \%$ of sleeping hours. However, unsurprisingly, while this window operation during the heating season improves IAQ considerably, there is also an adverse effect on heating demand for this highly-insulated flat (a heating load of $6.55 \mathrm{kWh} / \mathrm{m}^{2}$ for months of January and February compared to that of $0.95 \mathrm{kWh} / \mathrm{m}^{2}$ when windows remained closed in these months). Needless to say, this challenging trade-off between IAQ and heating energy demand, is one of the key arguments for greater

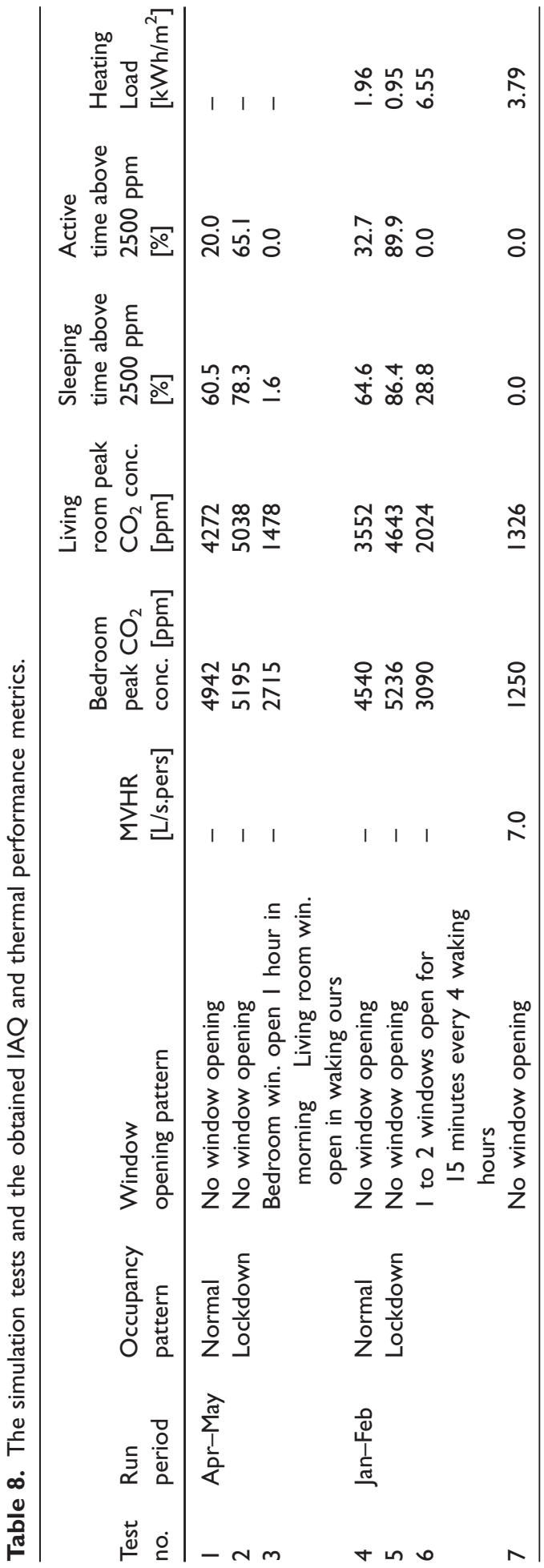




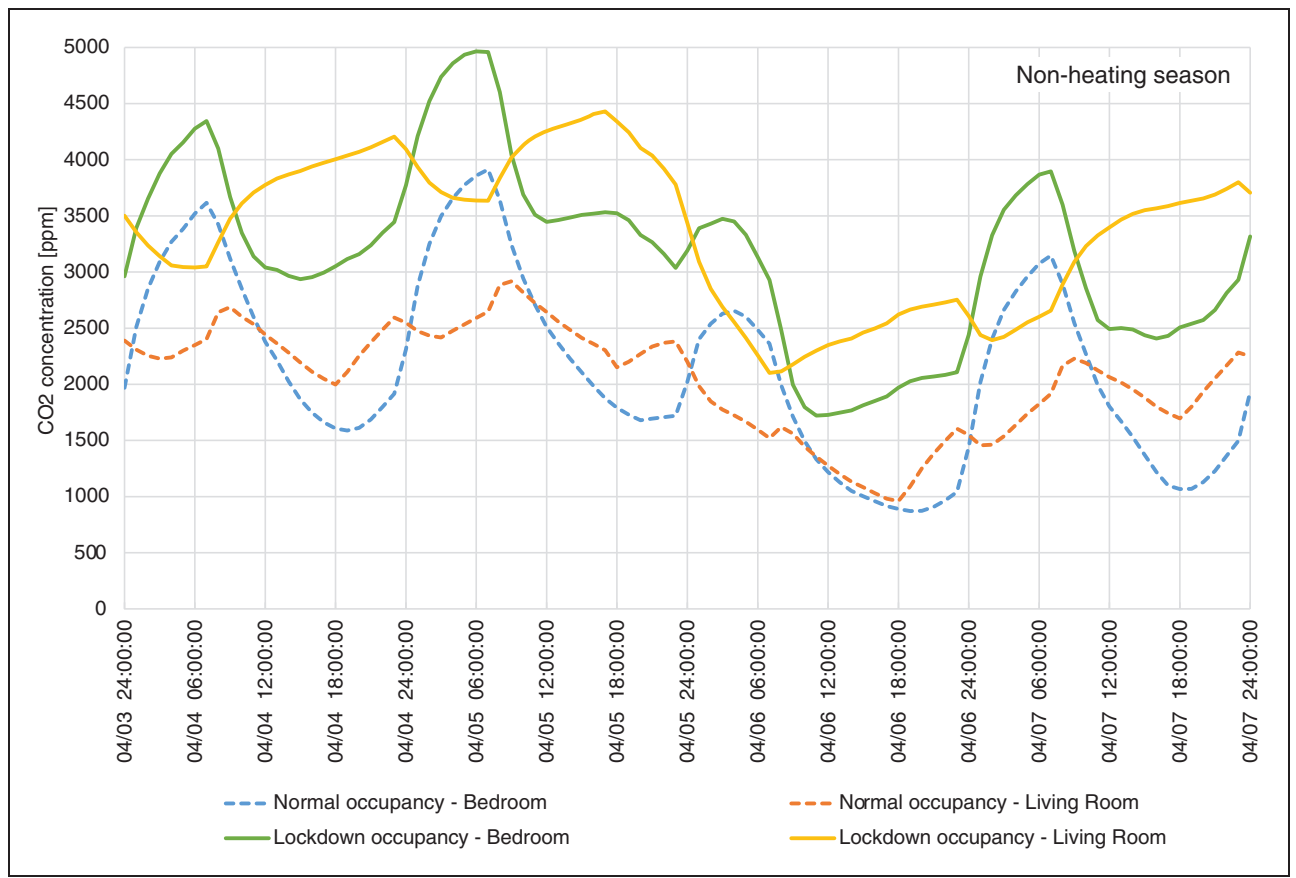

Figure 8. A 4-day section of simulation tests I \& 2 - Worst-case $\mathrm{CO}_{2}$ concentration in non-heating season without window operation and mechanical ventilation for normal and lockdown occupancy patterns.

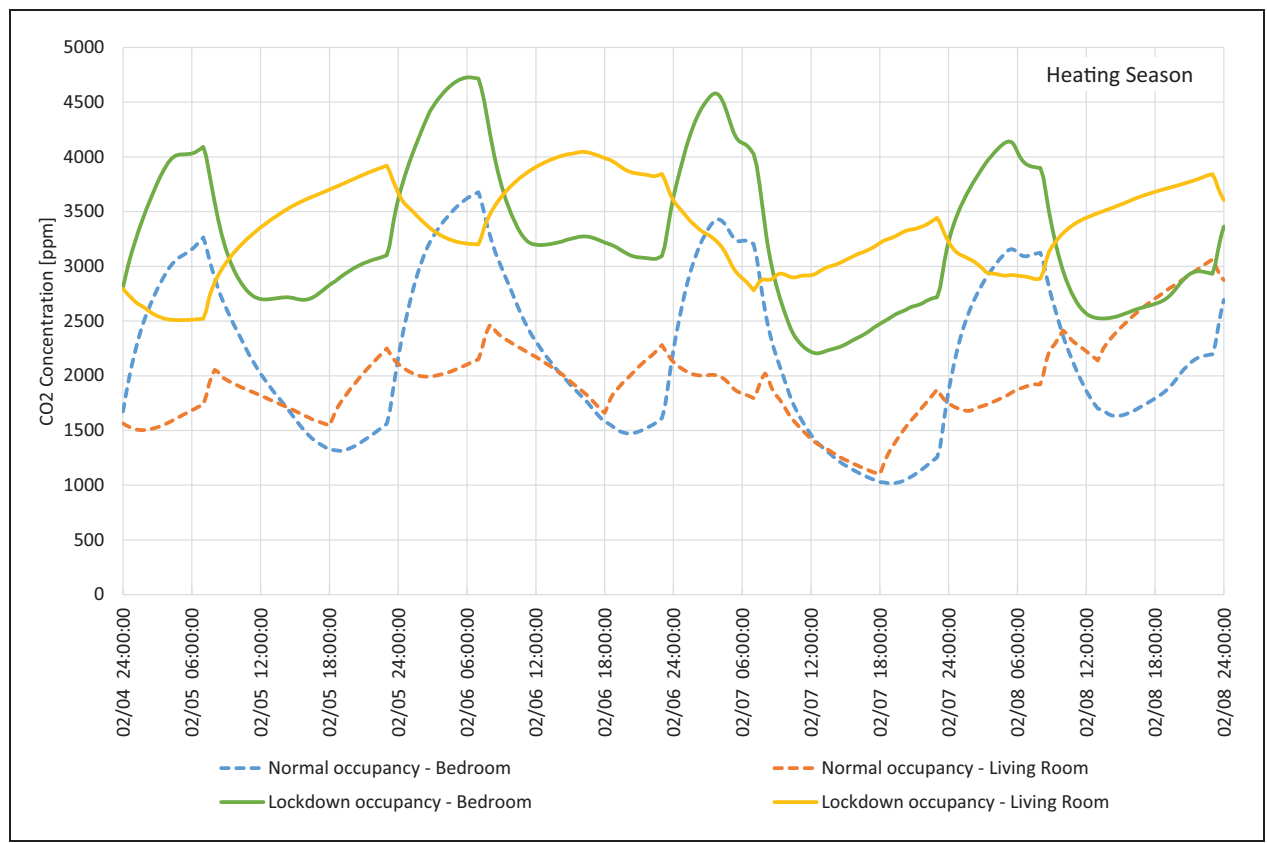

Figure 9. A 4-day section of simulation tests $4 \& 5$ - Worst-case $\mathrm{CO}_{2}$ concentration in heating season without window operation and mechanical ventilation for normal and lockdown occupancy patterns. 


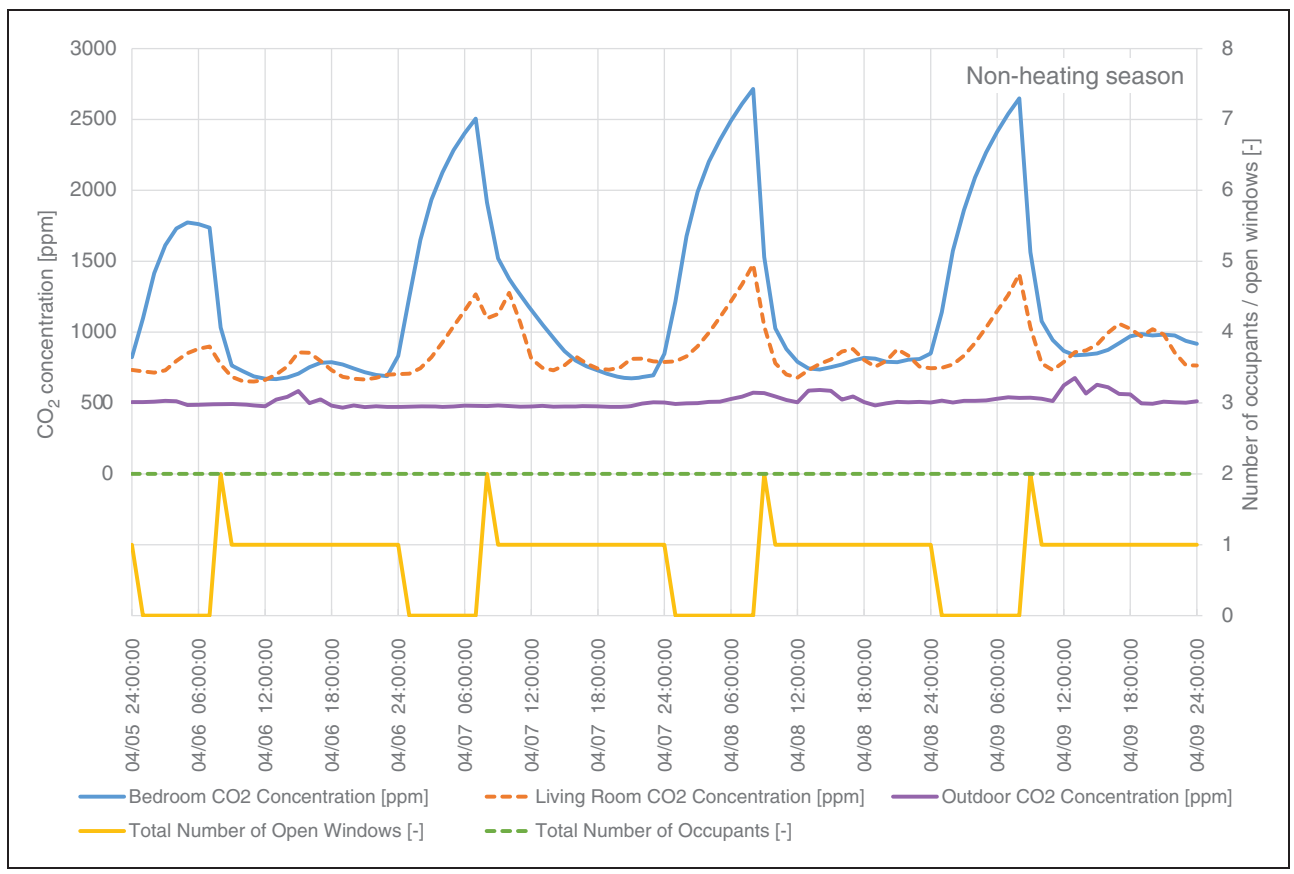

Figure 10. A 4-day section of simulation test 3 - Monitored outdoor and predicted indoor $\mathrm{CO}_{2}$ concentrations in non-heating season with lockdown occupancy pattern and opening of I to 2 windows during the day.

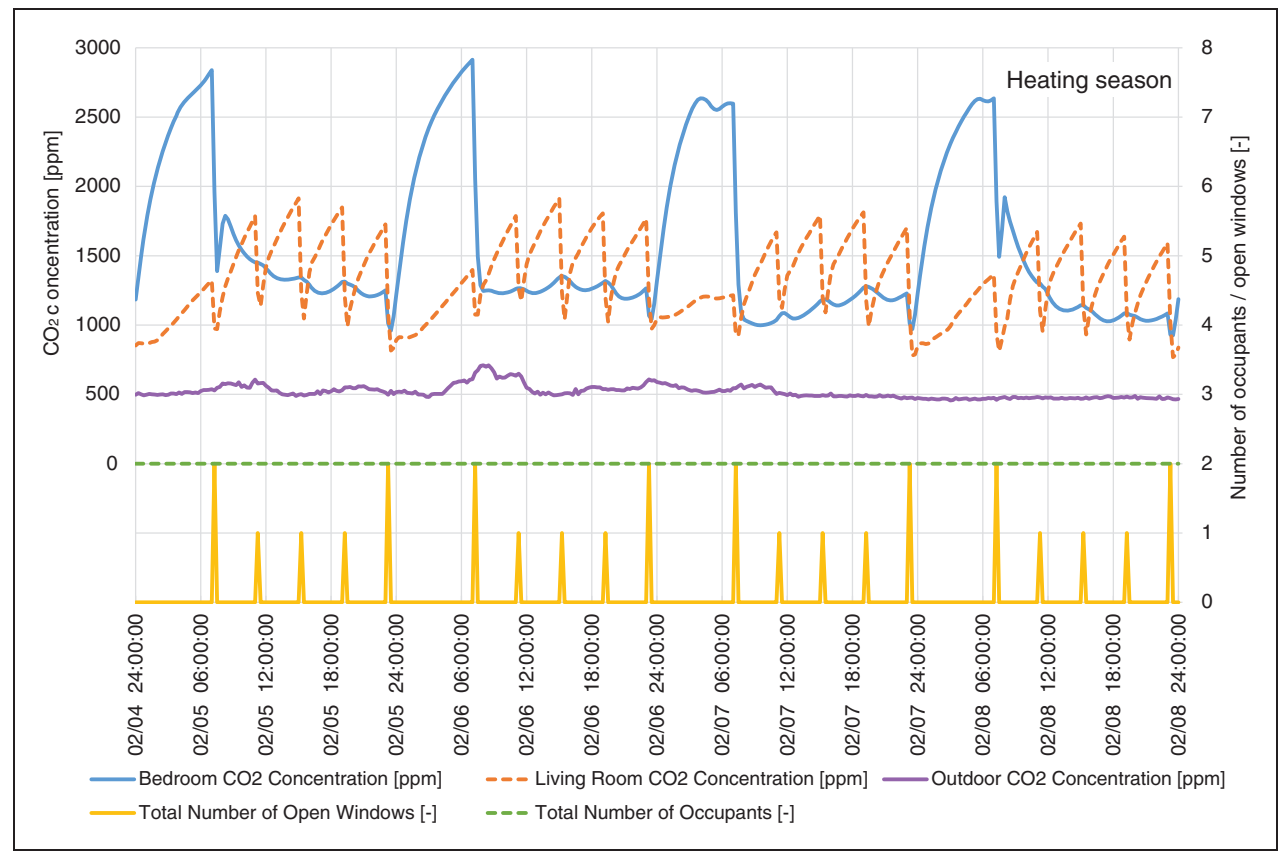

Figure II. A 4-day section of simulation test 6 - Monitored outdoor and predicted $\mathrm{CO}_{2}$ concentrations in heating season with lockdown occupancy pattern and daytime opening of I to 2 windows for periods of 15 min every $4 \mathrm{~h}$. 


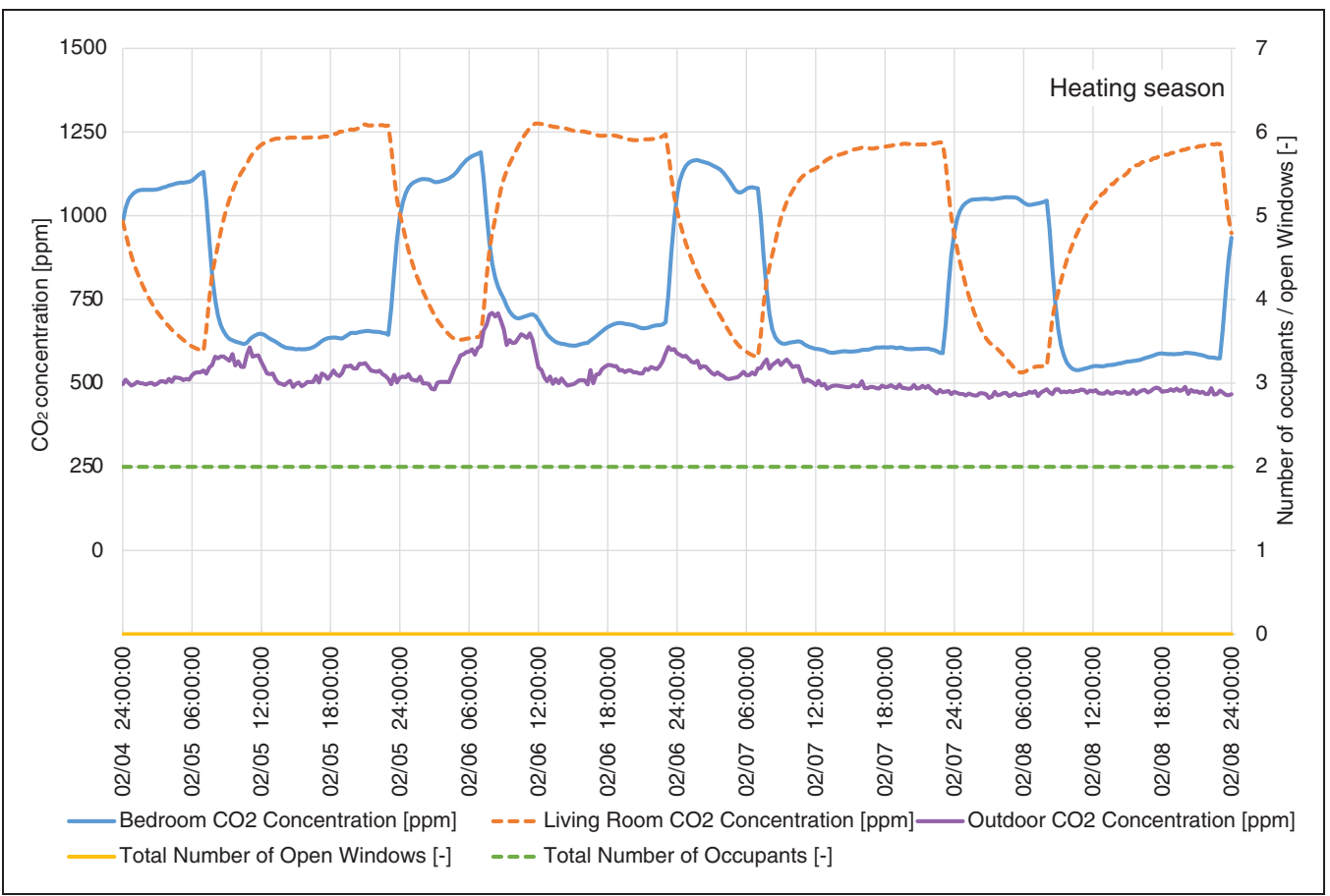

Figure 12. A 4-day section of simulation test 7 - Monitored outdoor and predicted $\mathrm{CO}_{2}$ concentrations in heating season with lockdown occupancy pattern and operation of MVHR delivering $7 \mathrm{~L} / \mathrm{s}$.person outdoor air.

use of mechanical ventilation with heat recovery. As can be seen in Table 8 and Figure 12, test number 7 demonstrates that a MHVR system (with a sensible heat recovery effectiveness of 0.75 and providing $7 \mathrm{~L} /$ s.person outdoor air), can maintain the $\mathrm{CO}_{2}$ concentrations in both rooms below $1400 \mathrm{ppm}$. It also reduces the heating demand by more than $40 \%$ compared to the solution based on natural ventilation in test number 6 .

\section{Conclusion}

This paper has shown that with the changing home occupancy patterns after the Covid-19 outbreak, indoor $\mathrm{CO}_{2}$ concentrations can rise significantly. At the same time, the results of the study suggested that the main environmental driving factor for window operation in both prelockdown and lockdown periods was indoor temperature. Nonetheless, the natural ventilation strategies tested on a flat with one-sided openings and the use of MVHR proved to be very effective to maintain acceptable IAQ at home.

\section{Declaration of conflicting interests}

The author(s) declared no potential conflicts of interest with respect to the research, authorship, and/or publication of this article.

\section{Funding}

The author(s) disclosed receipt of the following financial support for the research, authorship, and/or publication of this article: The study presented in this paper is funded by EPSRC IAA (Project number 559487) and CIBSE Support for Research.

\section{ORCID iDs}

Farhang Tahmasebi (D) https://orcid.org/0000-00015727-2646

Daniel Godoy Shimizu (D) https://orcid.org/00000002-6765-9606 


\section{References}

1. Wallace L. Total exposure assessment methodology (team) study: summary and analysis. Vol. 1. U.S. Environmental Protection Agency, Washington, D.C., 1987, EPA/600/6-87/002A (NTIS PB88100060).

2. Lim J-M, Jeong J-H, Lee J-H, et al. The analysis of PM2.5 and associated elements and their indoor/outdoor pollution status in an urban area. Indoor Air 2011; 21: 145-155.

3. Fromme H, Twardella D, Dietrich S, et al. Particulate matter in the indoor air of classrooms - exploratory results from Munich and surrounding area. Atmos Environ 2007; 41: 854-866.

4. Persily AK. Evaluating building IAQ and ventilation with indoor carbon dioxide. ASHRAE Trans 1997; 103.

5. Lipsett MJ, Shusterman DJ and Beard RR. Inorganic compounds of carbon, nitrogen, and oxygen. In: Clayton GD and Clayton FD (eds) Patty's industrial hygiene and toxicology. New York: John Wiley \& Sons, 1994, pp.4523-4554.

6. Erdmann CA and Apte MG. Mucous membrane and lower respiratory building related symptoms in relation to indoor carbon dioxide concentrations in the 100building BASE dataset. Indoor Air 2004; 14: 127-134.

7. Federspiel CC, Fisk WJ, Price PN, et al. Worker performance and ventilation in a call center: analyses of work performance data for registered nurses. Indoor Air 2004; 14: 41-50.

8. Milton DK, Glencross PM and Walters MD. Risk of sick leave associated with outdoor air supply rate, humidification, and occupant complaints. Indoor Air 2000; 10: 212-221.

9. Mudarri DH. Potential correction factors for interpreting $\mathrm{CO} 2$ measurements in buildings. ASHRAE Trans 1997; 103: 244-255.

10. Persily AK. Evaluating building IAQ and ventilation with carbon dioxide. ASHRAE Trans 1997; 103: 193-204.

11. Chatzidiakou L, Mumovic D and Summerfield A. Is $\mathrm{CO} 2$ a good proxy for indoor air quality in classrooms? Part 1: the interrelationships between thermal conditions, $\mathrm{CO} 2$ levels, ventilation rates and selected indoor pollutants. Build Serv Eng Res Technol 2015; 36: 2015.

12. Kajtár L and Levente H. Influence of carbon-dioxide concentration on human well-being and intensity of mental work. Q J Hung Meteorol Serv 2012; 116: $145-169$
13. Xu X, Lian Z, Shen J, et al. Experimental study on sleep quality affected by carbon dioxide concentration. Indoor Air 2020; 31(2): 440-453.

14. Mishra AK, van Ruitenbeek AM, Loomans MGLC, et al. Window/door opening-mediated bedroom ventilation and its impact on sleep quality of healthy, young adults. Indoor Air 2017; 28: 339-351.

15. Satish U, Mendell MJ, Shekhar K, et al. Is $\mathrm{CO} 2$ an indoor pollutant? Direct effects of low-to-moderate $\mathrm{CO} 2$ concentrations on human decision-making performance. Environ Health Perspect 2012; 120: 1671-1677.

16. Zhang X, Wargocki P, Lian Z, et al. Effects of exposure to carbon dioxide and bioeffluents on perceived air quality, self-assessed acute health symptoms and cognitive performance. Indoor Air 2016; 27: 47-64.

17. Zhang $X$, Wargocki $P$ and Lian $Z$. Human responses to carbon dioxide, a follow-up study at recommended exposure limits in non-industrial environments. Build Environ 2016; 100: 162-171.

18. Yan D, O'Brien W, Hong T, et al. Occupant behavior modeling for building performance simulation: current state and future challenges. Energy Build 2015; 107: 264-278.

19. Schweiker M. Understanding occupants' behaviour for energy efficiency in buildings. Curr Sustain Renew Energy Rep 2017; 4: 8-14.

20. Haldi F and Robinson D. Interactions with window openings by office occupants. Build Environ 2009; 44: 2378-2395.

21. Andersen R, Fabi V, Toftum J, et al. Window opening behaviour modelled from measurements in Danish dwellings. Build Environ 2013; 69: 101-113.

22. Tahmasebi F and Mahdavi A. On the utility of occupants' behavioural diversity information for building performance simulation: an exploratory case study. Energy Build 2018; 176: 380-389.

23. Tahmasebi F and Mahdavi A. 2013. A two-staged simulation model calibration approach to virtual sensors for building performance data. In: Proceedings of the 13th international conference of IBPSA, Chambery, France, 26-28 August 2013, pp. 25-28. International Building Performance Simulation Association.

24. Jain N, Esfand B, Stamp S, et al. Cross-sectoral assessment of the performance gap using calibrated building energy performance simulation. Energy Build 2015; 224: 110271. 